\title{
The End of Our Earth Is Certainly to Come: "When"? and "Why"?
}

\section{Kuo-Chen Chou}

Gordon Life Science Institute, Boston, Massachusetts, United States of America

Correspondence to: Kuo-Chen Chou, kcchou@gordonlifescience.org, kcchou38@gmail.com

Keywords: Coronavirus, Pandemic COVID-19, Atheists, Christians, Internet Institutes, Johann Pachelbel

Received: July 20, $2020 \quad$ Accepted: August 2, $2020 \quad$ Published: August 5, 2020

Copyright $\odot 2020$ by author(s) and Scientific Research Publishing Inc.

This work is licensed under the Creative Commons Attribution International License (CC BY 4.0).

http://creativecommons.org/licenses/by/4.0/

\section{(c) (i) Open Access}

\section{ABSTRACT}

Does the recent pandemic COVID-19 mean a very clear sign to eliminate our Earth? For such a "Living" and "Dying" problem, the answers from both "Atheists" and "Christians" are exactly the same. What we addressed here are of "When"? and "Why"?

\section{INTRODUCTION}

As of August-01-2020, nearly all the countries on the Earth have been affected by the Pandemic COVID-19: for USA alone the total number of the cases reported is 4,666,351 of which 155,930 leading to deaths. For United Kingdom, the corresponding numbers concerned are 303,952 and 46,119, respectively.

\section{FACTS AND DISCUSSIONS}

Its killing power is much stronger than the "Atomic Bomb" detonated over Japanese city of Hiroshima on August 6, 1945. The bombing killed 129,000 people.

It is also much more terrified than the Terrorists Attack on September 11, 2001 (often referred to "911"). The 911 attack resulted in 2977 fatalities, over 25,000 injuries, and substantial long-term health consequences.

The number of deaths in USA alone caused by the COVOD-19 has also significantly exceeded its military persons killed in any of its wars in history.

For the so-called "Atheists", including "Karl Max" and "Friedrich Engels" who are the founders of Communism theory, have stated in their books: "there is a Beginning, there must be an End", clearly indicating: "the Earth will eventually collide into some other planet and be completely crushed".

According to Bible, however, when our earth is close to its End, the following will be seen: "nation will rise against nation, and kingdom against kingdom. There will be great earthquakes, famines and pestilences in various places, and fearful events and great signs from Heaven."

Johann Pachelbel is one of the greatest composers. A tune composed by him has been played most frequently and constantly in the world. By choosing that very beautiful tune as the harmony, some female singers have been anxiously asking God of the two questions: "Why"? and "When"? The 1st question is 
about why there is the End of World" while the 2nd question is about when it will come true".

Now the answers to the two questions are very clear. Right before the World-End, Jesus will send out his angels to weed out those who are sin, evil and wicked. They will be thrown by the angels into the fiery furnace, where they will be weeping and gnashing of teeth. In contrast to this, the righteous will be raised to the Heaven.

Pestilences or Coronavirus disease 2019 (COVID-19) is an infectious disease caused by severe acute respiratory syndrome, which was first identified in December 2019 in Wuhan, Hubei, China. After April 2020 and causing about 4000 deaths, although no remarkable infectious cases reported in Wuhan. Unfortunately, the $2^{\text {nd }}$-wave coronavirus diseases have been also identified on Beijing during May 2020. This kind of originally from "East-Globe" or "Eastern hemisphere" to "West "Globe" or "Western Hemisphere" and then kicked back from the West to the East again, very much like playing "Tennis", "Ping-Pong" or "Badminton" ball. The extremely dangerous ball is none but "Coronavirus" or "Pestilences".

Since all the scientists working in a sharing laboratory of the Universities or most conversional Institutes must wear masks except those working in the "Internet Institute" (Figure 1) such as the "Gordon Life Scient Institute" [1-3]. And the results thus obtained will be of real usage for the other planet as indicated in [4].

Such expectation with deep belief has been widely and increasingly supported by many papers from different angles, corners, or aspects, particularly for the works based on the idea of "Pseudo Amino Acid Composition" or PseAAC" [5-80], the works based on the "5-steps Rule" [5-84], the works based on the "Wenxiang Diagram" [85-87], the works on the "HIV protease inhibitor prediction" [88-112], the works on the Post-translational modification (PTM) [113-122], the works on enzyme kinetics [123-152], the works on the protein subcellular location prediction [153-212], the works on enzyme kinetics [123-152], and the works on "Graphic Rules" [130, 134, 136, 138-141, 213-219].

Using graphic approaches to study biological and medical systems can provide an intuitive vision and useful insights for helping analyze complicated relations therein as shown by the eight master pieces of pioneering papers from the then Chairman of Nobel Prize Committee StureForsen [132, 213-215, 220-223] and many follow-up papers. This kind of insightful implication had been also demonstrated in [130, 224] and many follow-up publications [85, 86, 89-91, 96, 99, 121, 139, 140, 194, 195, 217, 225-263]. They are very useful for in-depth investigation into the topic of the current paper, and we will use them in our future efforts.

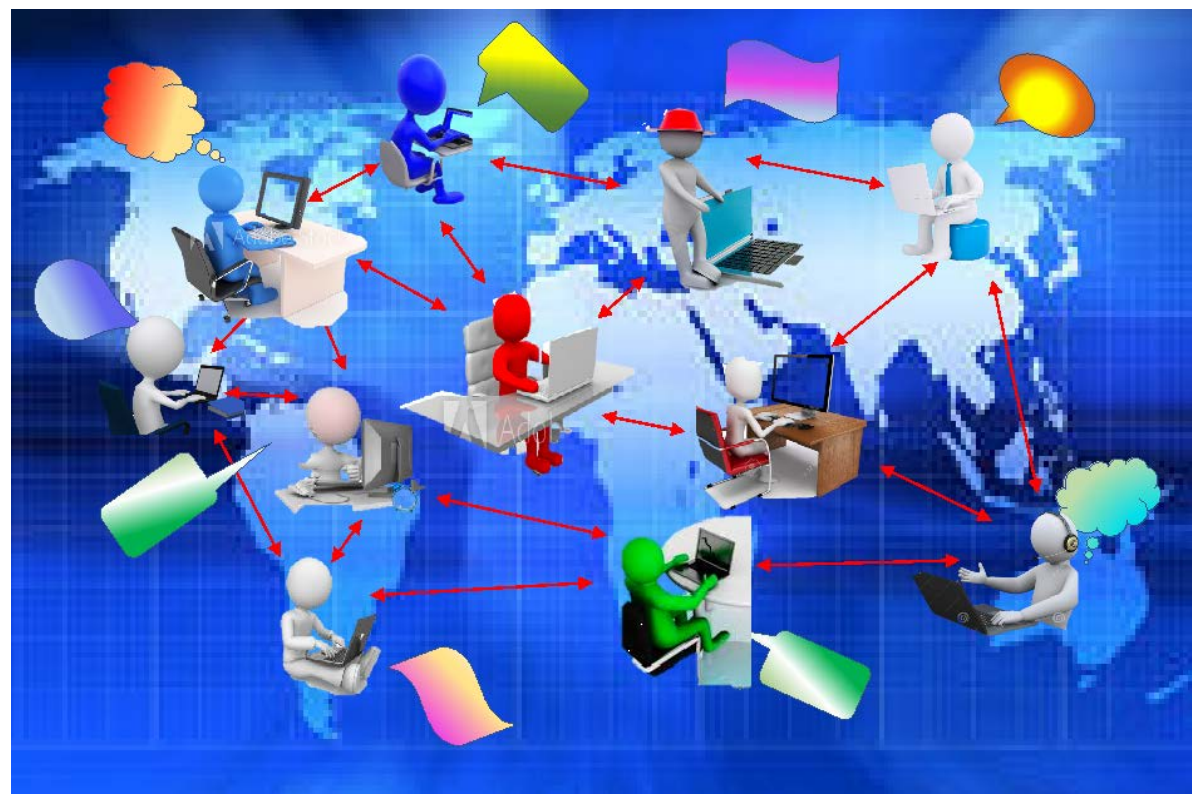

Figure 1. A schematic drawing to illustrate how the Internet Institute is working. 


\section{CONCLUSIONS}

After several waves of the killings as described in the Section 2, the speed to reach the End of our Earth will be accelerated exponentially. Within such a short period of time, it is the most effective and appropriate to acquire useful scientific knowledge via the "Internet Institutes".

\section{CONFLICTS OF INTEREST}

The author declares no conflicts of interest regarding the publication of this paper.

\section{REFERENCES}

1. K.C. Chou, The cradle of Gordon Life Science Institute and its development and driving force, Int J Biol Genetics, 1 (2019) 1-28.

2. K.C. Chou, Gordon Life Science Institute: Its philosophy, achievements, and perspective, Annals of Cancer Therapy and Pharmacology https://onomyscience.com/onomy/cancer_archive_volume2_issue2.html 2(2019) 001-026.

3. K.C. Chou, Intriguing Story about the Birth of Gordon Life Science Institute and its Development and Driving Force, J Retro Virol Anti Retro Virol, 1 (2019) 180002.

4. K.C. Chou, Gordon Life Science Institute and Its Impacts on Computational Biology and Drug Development, Natural Science, 12 (2020) 125-161.

5. L. Nanni, A. Lumini, Genetic programming for creating Chou's pseudo amino acid based features for submitochondria localization, Amino Acids, 34 (2008) 653-660.

6. B. Liao, Q. Xiang, D. Li, Incorporating Secondary Features into the General form of Chou's PseAAC for Predicting Protein Structural Class, Protein \& Peptide Letters, 19 (2012) 1133-1138.

7. X.W. Zhao, X.T. Li, Z.Q. Ma, M.H. Yin, Identify DNA-Binding Proteins with Optimal Chou's Amino Acid Composition, Protein \& Peptide Letters, 19 (2012) 398-405.

8. L. Nanni, A. Lumini, D. Gupta, A. Garg, Identifying bacterial virulent proteins by fusing a set of classifiers based on variants of Chou's pseudo amino acid composition and on evolutionary information, IEEE-ACM Transaction on Computational Biolology and Bioinformatics, 9 (2012) 467-475.

9. Zia-ur-Rehman, A. Khan, Identifying GPCRs and their Types with Chou's Pseudo Amino Acid Composition: An Approach from Multi-scale Energy Representation and Position Specific Scoring Matrix, Protein \& Peptide Letters, 19 (2012) 890-903.

10. X.Y. Sun, S.P. Shi, J.D. Qiu, S.B. Suo, S.Y. Huang, R.P. Liang, Identifying protein quaternary structural attributes by incorporating physicochemical properties into the general form of Chou's PseAAC via discrete wavelet transform, Molecular BioSystems, 8 (2012) 3178-3184.

11. C. Chen, Z.B. Shen, X.Y. Zou, Dual-Layer Wavelet SVM for Predicting Protein Structural Class Via the General Form of Chou's Pseudo Amino Acid Composition, Protein \& Peptide Letters, 19 (2012) 422-429.

12. S. Wan, M.W. Mak, S.Y. Kung, GOASVM: A subcellular location predictor by incorporating term-frequency gene ontology into the general form of Chou's pseudo amino acid composition, J. Theor. Biol., 323 (2013) 40-48.

13. T.H. Chang, L.C. Wu, T.Y. Lee, S.P. Chen, H.D. Huang, J.T. Horng, EuLoc: a web-server for accurately predict protein subcellular localization in eukaryotes by incorporating various features of sequence segments into the general form of Chou's PseAAC, Journal of Computer-Aided Molecular Design, 27 (2013) 91-103.

14. M.K. Gupta, R. Niyogi, M. Misra, An alignment-free method to find similarity among protein sequences via the general form of Chou's pseudo amino acid composition, SAR QSAR Environ Res, 24 (2013) 597-609. 
15. L. Kong, L. Zhang, J. Lv, Accurate prediction of protein structural classes by incorporating predicted secondary structure information into the general form of Chou's pseudo amino acid composition, J. Theor. Biol., 344 (2014) 12-18.

16. M. Hayat, N. Iqbal, Discriminating protein structure classes by incorporating Pseudo Average Chemical Shift to Chou's general PseAAC and Support Vector Machine, Computer methods and programs in biomedicine, 116 (2014) 184-192.

17. S. Ahmad, M. Kabir, M. Hayat, Identification of Heat Shock Protein families and J-protein types by incorporating Dipeptide Composition into Chou's general PseAAC, Computer methods and programs in biomedicine, 122 (2015) 165-174.

18. A. Dehzangi, R. Heffernan, A. Sharma, J. Lyons, K. Paliwal, A. Sattar, Gram-positive and Gram-negative protein subcellular localization by incorporating evolutionary-based descriptors into Chou's general PseAAC, J. Theor. Biol., 364 (2015) 284-294.

19. R. Sharma, A. Dehzangi, J. Lyons, K. Paliwal, T. Tsunoda, A. Sharma, Predict Gram-Positive and Gram-Negative Subcellular Localization via Incorporating Evolutionary Information and Physicochemical Features Into Chou's General PseAAC, IEEE Trans Nanobioscience, 14 (2015) 915-926.

20. M. Zhang, B. Zhao, X. Liu, Predicting industrial polymer melt index via incorporating chaotic characters into Chou's general PseAAC, Chemometrics and Intelligent Laboratory Systems (CHEMOLAB), 146 (2015) 232-240.

21. S.L. Zhang, Accurate prediction of protein structural classes by incorporating PSSS and PSSM into Chou's general PseAAC, Chemometrics and Intelligent Laboratory Systems (CHEMOLAB), 142 (2015) 28-35.

22. G.L. Fan, X.Y. Zhang, Y.L. Liu, Y. Nang, H. Wang, DSPMP: Discriminating secretory proteins of malaria parasite by hybridizing different descriptors of Chou's pseudo amino acid patterns, J. Comput. Chem., 36 (2015) 2317-2327.

23. F. Ali, M. Hayat, Classification of membrane protein types using Voting Feature Interval in combination with Chou's Pseudo Amino Acid Composition, J. Theor. Biol., 384 (2015) 78-83.

24. H. Tang, W. Chen, H. Lin, Identification of immunoglobulins using Chou's pseudo amino acid composition with feature selection technique, Mol Biosyst, 12 (2016) 1269-1275.

25. K. Ahmad, M. Waris, M. Hayat, Prediction of Protein Submitochondrial Locations by Incorporating Dipeptide Composition into Chou's General Pseudo Amino Acid Composition, J. Membr. Biol., 249 (2016) 293-304.

26. M. Behbahani, H. Mohabatkar, M. Nosrati, Analysis and comparison of lignin peroxidases between fungi and bacteria using three different modes of Chou's general pseudo amino acid composition, J. Theor. Biol., 411 (2016) 1-5.

27. G.L. Fan, Y.L. Liu, H. Wang, Identification of thermophilic proteins by incorporating evolutionary and acid dissociation information into Chou's general pseudo amino acid composition, J. Theor. Biol., 407 (2016) 138-142.

28. Z. Ju, J.Z. Cao, H. Gu, Predicting lysine phosphoglycerylation with fuzzy SVM by incorporating k-spaced amino acid pairs into Chou's general PseAAC, J. Theor. Biol., 397 (2016) 145-150.

29. A.K. Tiwari, Prediction of G-protein coupled receptors and their subfamilies by incorporating various sequence features into Chou's general PseAAC, Computer methods and programs in biomedicine, 134 (2016) 197-213.

30. C. Xu, D. Sun, S. Liu, Y. Zhang, Protein Sequence Analysis by Incorporating Modified Chaos Game and Physicochemical Properties into Chou's General Pseudo Amino Acid Composition, J. Theor. Biol., 406 (2016) 105-115.

31. H.L. Zou, X. Xiao, Classifying Multifunctional Enzymes by Incorporating Three Different Models into Chou's General Pseudo Amino Acid Composition (doi:10.1007/s00232-016-9904-3), J Membr Biol 249 (2016) 561-567. 
32. B. Yu, S. Li, W.Y. Qiu, C. Chen, R.X. Chen, L. Wang, M.H. Wang, Y. Zhang, Accurate prediction of subcellular location of apoptosis proteins combining Chou's PseAAC and PsePSSM based on wavelet denoising, Oncotarget, 8 (2017) 107640-107665.

33. M. Mousavizadegan, $\mathrm{H}$. Mohabatkar, Computational prediction of antifungal peptides via Chou's PseAAC and SVM, Journal of bioinformatics and computational biology, (2018) 1850016.

34. W. Zhao, L. Wang, T.X. Zhang, Z.N. Zhao, P.F. Du, A brief review on software tools in generating Chou's pseudo-factor representations for all types of biological sequences, Protein Pept Lett, 25 (2018) 822-829.

35. M.F. Sabooh, N. Iqbal, M. Khan, M. Khan, H.F. Maqbool, Identifying 5-methylcytosine sites in RNA sequence using composite encoding feature into Chou's PseKNC, J. Theor. Biol., 452 (2018) 1-9.

36. M. Arif, M. Hayat, Z. Jan, iMem-2LSAAC: A two-level model for discrimination of membrane proteins and their types by extending the notion of SAAC into Chou's pseudo amino acid composition, J. Theor. Biol., 442 (2018) 11-21.

37. S. Akbar, M. Hayat, iMethyl-STTNC: Identification of N(6)-methyladenosine sites by extending the Idea of SAAC into Chou's PseAAC to formulate RNA sequences, J. Theor. Biol., 455 (2018) 205-211.

38. X. Fu, W. Zhu, B. Liso, L. Cai, L. Peng, J. Yang, Improved DNA-binding protein identification by incorporating evolutionary information into the Chou's PseAAC, IEEE Access, 18 (2018) 43-66.

39. Y. Pan, S. Wang, Q. Zhang, Q. Lu, D. Su, Y. Zuo, L. Yang, Analysis and prediction of animal toxins by various Chou's pseudo components and reduced amino acid compositions, J. Theor. Biol., 462 (2019) 221-229.

40. M. Nosrati, H. Mohabatkar, M. Behbahani, Introducing of an integrated artificial neural network and Chou's pseudo amino acid composition approach for computational epitope-mapping of Crimean-Congo haemorrhagic fever virus antigens, International Immunopharmacology, 78 (2019) 106020.

41. M. Nosrati, H. Mohabatkar, M. Behbahani, Introducing of an integrated artificial neural network and Chou's pseudo amino acid composition approach for computational epitope-mapping of Crimean-Congo haemorrhagic fever virus antigens, Int Immunopharmacol, 78 (2020) 106020.

42. M. Tahir, M. Hayat, S.A. Khan, iNuc-ext-PseTNC: an efficient ensemble model for identification of nucleosome positioning by extending the concept of Chou's PseAAC to pseudo-tri-nucleotide composition, Molecular genetics and genomics: MGG, 294 (2019) 199-210.

43. M. Tahir, M. Hayat, iNuc-STNC: a sequence-based predictor for identification of nucleosome positioning in genomes by extending the concept of SAAC and Chou's PseAAC, Mol Biosyst 12 (2016) 2587-2593.

44. M. Tahir, H. Tayara, K.T. Chong, iRNA-PseKNC(2methyl): Identify RNA 2'-O-methylation sites by convolution neural network and Chou's pseudo components, J. Theor. Biol., 465 (2019) 1-6.

45. L. Zhang, L. Kong, iRSpot-ADPM: Identify recombination spots by incorporating the associated dinucleotide product model into Chou's pseudo components, J. Theor. Biol., 441 (2018) 1-8.

46. Y.S. Jiao, P.F. Du, Predicting protein submitochondrial locations by incorporating the positional-specific physicochemical properties into Chou's general pseudo-amino acid compositions, J. Theor. Biol., 416 (2017) 81-87.

47. Z. Ju, J.J. He, Prediction of lysine crotonylation sites by incorporating the composition of k-spaced amino acid pairs into Chou's general PseAAC, J Mol Graph Model, 77 (2017) 200-204.

48. M. Khan, M. Hayat, S.A. Khan, N. Iqbal, Unb-DPC: Identify mycobacterial membrane protein types by incorporating un-biased dipeptide composition into Chou's general PseAAC, J. Theor. Biol., 415 (2017) 13-19.

49. Y. Liang, S. Zhang, Predict protein structural class by incorporating two different modes of evolutionary information into Chou's general pseudo amino acid composition, J Mol Graph Model, 78 (2017) 110-117.

50. P.K. Meher, T.K. Sahu, V. Saini, A.R. Rao, Predicting antimicrobial peptides with improved accuracy by incorporating the compositional, physico-chemical and structural features into Chou's general PseAAC, Sci Rep, 7 
(2017) 42362.

51. W.R. Qiu, Q.S. Zheng, B.Q. Sun, X. Xiao, Multi-iPPseEvo: A Multi-label Classifier for Identifying Human Phosphorylated Proteins by Incorporating Evolutionary Information into Chou's General PseAAC via Grey System Theory, Mol Inform, 36 (2017) UNSP 1600085.

52. C. Xu, L. Ge, Y. Zhang, M. Dehmer, I. Gutman, Prediction of therapeutic peptides by incorporating q-Wiener index into Chou's general PseAAC, J Biomed Inform, doi:10.1016/j.jbi.2017.09.011 (2017).

53. A.H. Butt, N. Rasool, Y.D. Khan, Predicting membrane proteins and their types by extracting various sequence features into Chou's general PseAAC, Molecular biology reports, 18 (2018) 39-58.

54. A.W. Ghauri, Y.D. Khan, N. Rasool, S.A. Khan, K.C. Chou, pNitro-Tyr-PseAAC: Predict nitrotyrosine sites in proteins by incorporating five features into Chou's general PseAAC, Curr Pharm Des, 24 (2018) 4034-4043.

55. Z. Ju, S.Y. Wang, Prediction of citrullination sites by incorporating k-spaced amino acid pairs into Chou's general pseudo amino acid composition, Gene, 664 (2018) 78-83.

56. M.S. Krishnan, Using Chou's general PseAAC to analyze the evolutionary relationship of receptor associated proteins (RAP) with various folding patterns of protein domains, J. Theor. Biol., 445 (2018) 62-74.

57. Y. Liang, S. Zhang, Identify Gram-negative bacterial secreted protein types by incorporating different modes of PSSM into Chou's general PseAAC via Kullback-Leibler divergence, J. Theor. Biol., 454 (2018) 22-29.

58. J. Mei, Y. Fu, J. Zhao, Analysis and prediction of ion channel inhibitors by using feature selection and Chou's general pseudo amino acid composition, J. Theor. Biol., 456 (2018) 41-48.

59. J. Mei, J. Zhao, Analysis and prediction of presynaptic and postsynaptic neurotoxins by Chou's general pseudo amino acid composition and motif features, J. Theor. Biol., 427 (2018) 147-153.

60. S.M. Rahman, S. Shatabda, S. Saha, M. Kaykobad, M. Sohel Rahman, DPP-PseAAC: A DNA-binding Protein Prediction model using Chou's general PseAAC, J. Theor. Biol., 452 (2018) 22-34.

61. E.S. Sankari, D.D. Manimegalai, Predicting membrane protein types by incorporating a novel feature set into Chou's general PseAAC, J. Theor. Biol., 455 (2018) 319-328.

62. A. Srivastava, R. Kumar, M. Kumar, BlaPred: predicting and classifying beta-lactamase using a 3-tier prediction system via Chou's general PseAAC, J. Theor. Biol., 457 (2018) 29-36.

63. S. Zhang, X. Duan, Prediction of protein subcellular localization with oversampling approach and Chou's general PseAAC, J. Theor. Biol., 437 (2018) 239-250.

64. S. Adilina, D.M. Farid, S. Shatabda, Effective DNA binding protein prediction by using key features via Chou's general PseAAC, J. Theor. Biol., 460 (2019) 64-78.

65. M. Awais, W. Hussain, Y.D. Khan, N. Rasool, S.A. Khan, K.C. Chou, iPhosH-PseAAC: Identify phosphohistidine sites in proteins by blending statistical moments and position relative features according to the Chou's 5-step rule and general pseudo amino acid composition, IEEE/ACM Trans Comput Biol Bioinform, 19 (2019) $1-21$.

66. M. Behbahani, M. Nosrati, M. Moradi, H. Mohabatkar, Using Chou's General Pseudo Amino Acid Composition to Classify Laccases from Bacterial and Fungal Sources via Chou's Five-Step Rule, Appl. Biochem. Biotechnol., 190 (2019) 1035-1048.

67. G. Chen, M. Cao, J. Yu, X. Guo, S. Shi, Prediction and functional analysis of prokaryote lysine acetylation site by incorporating six types of features into Chou's general PseAAC, J. Theor. Biol., 461 (2019) 92-101.

68. A. Ehsan, M.K. Mahmood, Y.D. Khan, O.M. Barukab, S.A. Khan, K.C. Chou, iHyd-PseAAC (EPSV): Identify hydroxylation sites in proteins by extracting enhanced position and sequence variant feature via Chou's 5-step rule and general pseudo amino acid composition, Current Genomics, 20 (2019) 124-133. 
69. W. Hussain, S.D. Khan, N. Rasool, S.A. Khan, K.C. Chou, SPalmitoylC-PseAAC: A sequence-based model developed via Chou's 5-steps rule and general PseAAC for identifying S-palmitoylation sites in proteins, Anal. Biochem., 568 (2019) 14-23.

70. W. Hussain, Y.D. Khan, N. Rasool, S.A. Khan, K.C. Chou, SPrenylC-PseAAC: A sequence-based model developed via Chou's 5-steps rule and general PseAAC for identifying S-prenylation sites in proteins, J. Theor. Biol., 468 (2019) 1-11.

71. Z. Jun, S.Y. Wang, Identify Lysine Neddylation Sites Using Bi-profile Bayes Feature Extraction via the Chou's 5-steps Rule and General Pseudo Components, Current Genomics, 20 (2019) 592-601.

72. R. Liang, J. Xie, C. Zhang, M. Zhang, H. Huang, H. Huo, X. Cao, B. Niu, Identifying Cancer Targets Based on Machine Learning Methods via Chou's 5-steps Rule and General Pseudo Components, Current Topics in Medicnal Chemistry, 19 (2019) 2301-2317.

73. Y. Shen, J. Tang, F. Guo, Identification of protein subcellular localization via integrating evolutionary and physicochemical information into Chou's general PseAAC, J. Theor. Biol., 462 (2019) 230-239.

74. L. Wang, R. Zhang, Y. Mu, Fu-SulfPred: Identification of Protein S-sulfenylation Sites by Fusing Forests via Chou's General PseAAC, J. Theor. Biol., 461 (2019) 51-58.

75. X. Xiao, X. Cheng, G. Chen, Q. Mao, K.C. Chou, pLoc_bal-mVirus: Predict Subcellular Localization of Multi-Label Virus Proteins by Chou's General PseAAC and IHTS Treatment to Balance Training Dataset, Med Chem, 15 (2019) 496-509.

76. S. Akbar, A.U. Rahman, M. Hayat, S. M., cACP: Classifying anticancer peptides using discriminative intelligent model via Chou's 5-step rules and general pseudo components, Chemometrics and Intelligent Laboratory (CHEMOLAB), 196 (2020) 103912.

77. M. Behbahani, M. Nosrati, M. Moradi, H. Mohabatkar, Using Chou's General Pseudo Amino Acid Composition to Classify Laccases from Bacterial and Fungal Sources via Chou's Five-Step Rule, Appl. Biochem. Biotechnol., 190 (2020) 1035-1048.

78. Z. Ju, S.Y. Wang, Prediction of lysine formylation sites using the composition of k-spaced amino acid pairs via Chou's 5-steps rule and general pseudo components, Genomics, 112 (2020) 859-866.

79. M. Kabir, S. Ahmad, M. Iqbal, M. Hayat, iNR-2L: A two-level sequence-based predictor developed via Chou's 5-steps rule and general PseAAC for identifying nuclear receptors and their families, Genomics, 112 (2020) 276-285.

80. Y.D. Khan, N. Amin, W. Hussain, N. Rasool, S.A. Khan, K.C. Chou, iProtease-PseAAC(2L): A two-layer predictor for identifying proteases and their types using Chou's 5-step-rule and general PseAAC, Anal. Biochem., 588 (2020) 113477.

81. P. Xuan, H. Cui, T. Shen, N. Sheng, T. Zhang, HeteroDualNet: A Dual Convolutional Neural Network With Heterogeneous Layers for Drug-Disease Association Prediction via Chou's Five-Step Rule, 10 (2019) 1301.

82. P. Xuan, H. Cui, T. Shen, N. Sheng, T. Zhang, HeteroDualNet: A Dual Convolutional Neural Network With Heterogeneous Layers for Drug-Disease Association Prediction via Chou's Five-Step Rule, Frontiers in Pharmacology, 10 (2019) 1301.

83. Y. Zou, Y. Ding, J. Tang, F. Fei Guo, L. Peng, FKRR-MVSF: A fuzzy kernel ridge regression model for identifying DNA-binding proteins by multi-view sequence features via Chou's five-step rule, Int J Mol Sci, 2019 (2019) $1-14$.

84. H. Mohabatkar, S. Ebrahimi, M. Moradi, Using Chou's Five-steps Rule to Classify and Predict Glutathione S-transferases with Different Machine Learning Algorithms and Pseudo Amino Acid Composition, International Journal of Peptide Research and Therapeutics, 2020 (2020) 1-17. 
85. K.C. Chou, W.Z. Lin, X. Xiao, Wenxiang: a web-server for drawing wenxiang diagrams Natural Science, 3 (2011) 862-865

86. G.P. Zhou, The disposition of the LZCC protein residues in wenxiang diagram provides new insights into the protein-protein interaction mechanism, J. Theor. Biol., 284 (2011) 142-148.

87. G.P. Zhou, D. Chen, S. Liao, R.B. Huang, Recent Progresses in Studying Helix-Helix Interactions in Proteins by Incorporating the Wenxiang Diagram into the NMR Spectroscopy, Curr Top Med Chem, 16 (2016) 581-590.

88. K.C. Chou, C.T. Zhang, Diagrammatization of codon usage in 339 HIV proteins and its biological implication, AIDS Research and Human Retroviruses, 8 (1992) 1967-1976.

89. I.W. Althaus, J.J. Chou, A.J. Gonzales, M.R. Diebel, K.C. Chou, F.J. Kezdy, D.L. Romero, P.A. Aristoff, W.G. Tarpley, F. Reusser, Steady-state kinetic studies with the non-nucleoside HIV-1 reverse transcriptase inhibitor U-87201E, J. Biol. Chem., 268 (1993) 6119-6124.

90. I.W. Althaus, J.J. Chou, A.J. Gonzales, M.R. Diebel, K.C. Chou, F.J. Kezdy, D.L. Romero, P.A. Aristoff, W.G. Tarpley, F. Reusser, Kinetic studies with the nonnucleoside HIV-1 reverse transcriptase inhibitor U-88204E, Biochemistry, 32 (1993) 6548-6554.

91. I.W. Althaus, A.J. Gonzales, J.J. Chou, M.R. Diebel, K.C. Chou, F.J. Kezdy, D.L. Romero, P.A. Aristoff, W.G. Tarpley, F. Reusser, The quinoline U-78036 is a potent inhibitor of HIV-1 reverse transcriptase, J. Biol. Chem., 268 (1993) 14875-14880.

92. J.J. Chou, Predicting cleavability of peptide sequences by HIV protease via correlation-angle approach, J. Protein Chem., 12 (1993) 291-302.

93. K.C. Chou, A vectorized sequence-coupling model for predicting HIV protease cleavage sites in proteins, J. Biol. Chem., 268 (1993) 16938-16948.

94. K.C. Chou, C.T. Zhang, Studies on the specificity of HIV protease: an application of Markov chain theory, J. Protein Chem., 12 (1993) 709-724.

95. K.C. Chou, C.T. Zhang, F.J. Kezdy, A vector approach to predicting HIV protease cleavage sites in proteins, Proteins: Struct., Funct., Genet., 16 (1993) 195-204.

96. I.W. Althaus, J.J. Chou, A.J. Gonzales, M.R. Diebel, K.C. Chou, F.J. Kezdy, D.L. Romero, P.A. Aristoff, W.G. Tarpley, F. Reusser, Steady-state kinetic studies with the polysulfonate U-9843, an HIV reverse transcriptase inhibitor, Cellular and Molecular Life Science (Experientia), 50 (1994) 23-28.

97. C.T. Zhang, K.C. Chou, An alternate-subsite-coupled model for predicting HIV protease cleavage sites in proteins, Protein Eng., 7 (1994) 65-73.

98. T.B. Thompson, K.C. Chou, C. Zheng, Neural network prediction of the HIV-1 protease cleavage sites, J Theor Biol 177 (1995) 369-379.

99. I.W. Althaus, K.C. Chou, K.M. Franks, M.R. Diebel, F.J. Kezdy, D.L. Romero, R.C. Thomas, P.A. Aristoff, W.G. Tarpley, F. Reusser, The benzylthio-pyrididine U-31,355, a potent inhibitor of HIV-1 reverse transcriptase, Biochem. Pharmacol., 51 (1996) 743-750.

100. K.C. Chou, A.L. Tomasselli, I.M. Reardon, R.L. Heinrikson, Predicting HIV protease cleavage sites in proteins by a discriminant function method, Proteins: Struct., Funct., Genet., 24 (1996) 51-72.

101. Y.D. Cai, K.C. Chou, Artificial neural network model for HIV protease cleavage sites in proteins, Advances in Engineering Software, 29 (1998) 119-128.

102. Y.D. Cai, H. Yu, K.C. Chou, Using neural network for prediction of HIV protease cleavage sites in proteins, J. Protein Chem., 17 (1998) 607-615.

103. Y.D. Cai, X.J. Liu, X.B. Xu, K.C. Chou, Support Vector Machines for predicting HIV protease cleavage sites in 
protein, J. Comput. Chem., 23 (2002) 267-274.

104. S. Sirois, T. Sing, K.C. Chou, Review: HIV-1 gp120 V3 loop for structure-based drug design, Current Protein and Peptide Science, 6 (2005) 413-422.

105. S. Sirois, C.M. Tsoukas, K.C. Chou, D.Q. Wei, C. Boucher, G.E. Hatzakis, Selection of Molecular Descriptors with Artificial Intelligence for the Understanding of HIV-1 Protease Peptidomimetic Inhibitors-activity, Medicinal Chemistry, 1 (2005) 173-184.

106. W.N. Gao, D.Q. Wei, Y. Li, H. Gao, W.R. Xu, A.X. Li, K.C. Chou, Agaritine and its derivatives are potential inhibitors against HIV proteases, Medicinal Chemistry, 3 (2007) 221-226.

107. S. Sirois, M. Touaibia, K.C. Chou, R. Roy, Review: Glycosylation of HIV-1 gp120 V3 loop: towards the rational design of a synthetic carbohydrate vaccine, Current Medicinal Chemistry, 14 (2007) 3232-3242.

108. H.B. Shen, K.C. Chou, HIVcleave: a web-server for predicting HIV protease cleavage sites in proteins, Anal. Biochem., 375 (2008) 388-390.

109. J. Dev, D. Park, Q. Fu, J. Chen, H.J. Ha, F. Ghantous, T. Herrmann, W. Chang, Z. Liu, G. Frey, M.S. Seaman, B. Chen, J.J. Chou, Structural Basis for Membrane Anchoring of HIV-1 Envelope Spike, Science 353 (2016) 172-175.

110. B. Chen, J.J. Chou, Structure of the transmembrane domain of HIV-1 envelope glycoprotein, FEBS J, 284 (2017) 1171-1177.

111. A. Piai, J. Dev, Q. Fu, J.J. Chou, Stability and Water Accessibility of the Trimeric Membrane Anchors of the HIV-1 Envelope Spikes, J. Am. Chem. Soc., 139 (2017) 18432-18435.

112. Q. Fu, M.M. Shaik, Y. Cai, F. Ghantous, A. Piai, H. Peng, S. Rits-Volloch, Z. Liu, S.C. Harrison, M.S. Seaman, B. Chen, J.J. Chou, Structure of the membrane proximal external region of HIV-1 envelope glycoprotein, Proc. Natl. Acad. Sci. U. S. A., 115 (2018) E8892-E8899.

113. F. Li, C. Fan, T.T. Marquez-Lago, A.L. Jerico Revote, C. Jia, Y. Zhu, A.I. Smith, K.C. Chou, G.I. Webb, Q. Liu, L. Wei, J. Li, J. Song, PRISM: a comprehensive 3D structure database for post-translational modifications and mutations with functional impact, bioRxiv (Cold Spring Harbor Laboratory), doi: dx.doi.org/10.1101/523.

114. Q.S. Du, S.Q. Wang, D.Q. Wei, Y. Zhu, H. Guo, S. Sirois, K.C. Chou, Polyprotein Cleavage Mechanism of SARS CoV Mpro and Chemical Modification of Octapeptide, Peptides, 25 (2004) 1857-1864.

115. Q.S. Du, S. Wang, D.Q. Wei, S. Sirois, K.C. Chou, Molecular modelling and chemical modification for finding peptide inhibitor against SARS CoV Mpro, Anal. Biochem., 337 (2005) 262-270.

116. Q.S. Du, S.Q. Wang, Z.Q. Jiang, W.N. Gao, Y.D. Li, D.Q. Wei, K.C. Chou, Application of bioinformatics in search for cleavable peptides of SARS-CoV Mpro and chemical modification of octapeptides, Medicinal Chemistry, 1 (2005) 209-213.

117. Y. Xu, K.C. Chou, Recent progress in predicting posttranslational modification sites in proteins, Curr Top Med Chem, 16 (2016) 591-603.

118. P. Feng, H. Ding, H. Yang, W. Chen, H. Lin, K.C. Chou, iRNA-PseColl: Identifying the occurrence sites of different RNA modifications by incorporating collective effects of nucleotides into PseKNC, Molecular Therapy Nucleic Acids 7(2017) 155-163.

119. W. Chen, P. Feng, H. Yang, H. Ding, H. Lin, K.C. Chou, iRNA-3typeA: identifying 3-types of modification at RNA's adenosine sites, Molecular Therapy: Nucleic Acid, 11 (2018) 468-474.

120. Z. Chen, X. Liu, F. Li, C. Li, T. Marquez-Lago, A. Leier, T. Akutsu, G.I. Webb, D. Xu, A.I. Smith, L. Li, K.C. Chou, J. Song, Large-scale comparative assessment of computational predictors for lysine post-translational modification sites, Brief in Bioinform, doi: 10.1093/bib/bby089 (2018).

121. K.C. Chou, Artificial intelligence (AI) tools constructed via the 5-steps rule for predicting post-translational 
modifications, Trends in Artificial Inttelengence (TIA), 3 (2019) 60-74.

122. K.C. Chou, Progresses in predicting post-translational modification (2019), International Journal of Peptide Research and Therapeutics (IJPRT), 26 (2020) 873-888.

123. K.C. Chou, S.P. Jiang, Studies on the rate of diffusion-controlled reactions of enzymes, Scientia Sinica, 17 (1974) 664-680.

124. K.C. Chou, Studies on the enzyme kinetics of the cavity-active site, Acta Biochimica et Biophysica Sinica, 7 (1975) 95-103.

125. K.C. Chou, C.K. Kuo, T.T. Li, The quantitative relations between diffusion-controlled reaction rate and characteristic parameters in enzyme-substrate reaction system: 2. Charged substrates, Scientia Sinica, 18 (1975) 366-380.

126. K.C. Chou, The kinetics of the combination reaction between enzyme and substrate, Scientia Sinica, 19 (1976) 505-528.

127. T.T. Li, K.C. Chou, The quantitative relations between diffusion-controlled reaction rate and characteristic parameters in enzyme-substrate reaction system: 1. Neutral substrates, Scientia Sinica, 19 (1976) 117-136.

128. K.C. Chou, The kinetics of the combination reaction between enzyme and substrate: 1 . Stochastic analysis, activation energy and multiple-active-site, Acta Biochimica et Biophysica Sinica, 9 (1977) 79-94.

129. K.C. Chou, The kinetics of the combination reaction between enzyme and substrate: 2. Multi-barrier reaction and measuring signal, Acta Biochimica et Biophysica Sinica, 9 (1977) 175-186.

130. K.C. Chou, S.P. Jiang, W.M. Liu, C.H. Fee, Graph theory of enzyme kinetics: 1. Steady-state reaction system, Scientia Sinica, 22 (1979) 341-358.

131. K.C. Chou, A new schematic method in enzyme kinetics, Eur. J. Biochem., 113 (1980) 195-198.

132. T.T. Li, K.C. Chou, S. Forsen, The flow of substrate molecules in fast enzyme-catalyzed reaction systems, Chemica Scripta, 16 (1980) 192-196.

133. K.C. Chou, Two new schematic rules for rate laws of enzyme-catalyzed reactions, J. Theor. Biol., 89 (1981) 581-592.

134. K.C. Chou, A new graphical rule for rate laws of enzyme reactions with branched pathways, Canadian Journal of Biochemistry, 59 (1981) 757-761.

135. K.C. Chou, T.T. Li, G.Q. Zhou, A semi-analytical expression for the concentration distribution of substrate molecules in fast, enzyme-catalyzed reaction systems, Biochim. Biophys. Acta, 657 (1981) 304-308.

136. K.C. Chou, W.M. Liu, Graphical rules for non-steady state enzyme kinetics, J. Theor. Biol., 91 (1981) 637-654.

137. K.C. Chou, G.P. Zhou, Role of the protein outside active site on the diffusion-controlled reaction of enzyme, Journal of American Chemical Society, 104 (1982) 1409-1413.

138. K.C. Chou, Advances in graphical methods of enzyme kinetics, Biophysical Chemistry, 17 (1983) 51-55.

139. K.C. Chou, Graphic rules in steady and non-steady enzyme kinetics, J. Biol. Chem., 264 (1989) 12074-12079.

140. K.C. Chou, Review: Applications of graph theory to enzyme kinetics and protein folding kinetics. Steady and non-steady state systems, Biophysical Chemistry, 35 (1990) 1-24.

141. K.C. Chou, Graphic rule for non-steady-state enzyme kinetics and protein folding kinetics, Journal of Mathematical Chemistry, 12 (1993) 97-108.

142. K.C. Chou, D.W. Elrod, Prediction of enzyme family classes, Journal of Proteome Research, 2 (2003) 183-190.

143. K.C. Chou, Y.D. Cai, A novel approach to predict active sites of enzyme molecules, Proteins: Struct., Funct., Genet., 55 (2004) 77-82. 
144. K.C. Chou, Y.D. Cai, Predicting enzyme family class in a hybridization space, Protein Science, 13 (2004) 2857-2863.

145. K.C. Chou, Y.D. Cai, Using GO-PseAA predictor to predict enzyme sub-class, Biochemical and Biophysical Research Communications (BBRC), 325 (2004) 506-509.

146. Y.D. Cai, K.C. Chou, Using functional domain composition to predict enzyme family classes, Journal of Proteome Research, 4 (2005) 109-111.

147. Y.D. Cai, K.C. Chou, Predicting enzyme subclass by functional domain composition and pseudo amino acid composition, Journal of Proteome Research, 4 (2005) 967-971.

148. Y.D. Cai, G.P. Zhou, K.C. Chou, Predicting enzyme family classes by hybridizing gene product composition and pseudo amino acid composition, J. Theor. Biol., 234 (2005) 145-149.

149. K.C. Chou, Using amphiphilic pseudo amino acid composition to predict enzyme subfamily classes, Bioinformatics, 21 (2005) 10-19.

150. H.B. Shen, K.C. Chou, EzyPred: A top-down approach for predicting enzyme functional classes and subclasses, Biochem Biophys Res Comm (BBRC), 364 (2007) 53-59.

151. H. Wei, R. Zhang, C. Wang, H. Zheng, K.C. Chou, D.Q. Wei, Molecular insights of SAH enzyme catalysis and their implication for inhibitor design, J. Theor. Biol., 244 (2007) 692-702.

152. J.L. Min, X. Xiao, K.C. Chou, iEzy-Drug: A web server for identifying the interaction between enzymes and drugs in cellular networking, BioMed Research International (BMRI), 2013 (2013) 701317.

153. K.C. Chou, D.W. Elrod, Using discriminant function for prediction of subcellular location of prokaryotic proteins, Biochem Biophys Res Commun (BBRC), 252 (1998) 63-68.

154. K.C. Chou, D.W. Elrod, Protein subcellular location prediction, Protein Eng., 12 (1999) 107-118.

155. K.C. Chou, D.W. Elrod, Prediction of membrane protein types and subcellular locations, Proteins: Struct., Funct., Genet., 34 (1999) 137-153.

156. K.C. Chou, Review: Prediction of protein structural classes and subcellular locations, Current Protein and Peptide Science, 1 (2000) 171-208.

157. K.C. Chou, Prediction of protein subcellular locations by incorporating quasi-sequence-order effect, Biochem Biophys Res Comm (BBRC), 278 (2000) 477-483.

158. Y.D. Cai, X.J. Liu, X.B. Xu, K.C. Chou, Support vector machines for prediction of protein subcellular location by incorporating quasi-sequence-order effect, J. Cell. Biochem., 84 (2002) 343-348.

159. Y.D. Cai, K.C. Chou, Nearest neighbour algorithm for predicting protein subcellular location by combining functional domain composition and pseudo amino acid composition, Biochem Biophys Res Comm (BBRC), 305 (2003) 407-411.

160. K.C. Chou, Y.D. Cai, Prediction and classification of protein subcellular location: sequence-order effect and pseudo amino acid composition, Journal of Cellular Biochemistry (Addendum, ibid. 2004, 91, 1085), 90 (2003) $1250-1260$.

161. K.C. Chou, Y.D. Cai, Prediction of protein subcellular locations by GO-FunD-PseAA predicor, Biochemical and Biophysical Research Communications (BBRC), 320 (2004) 1236-1239.

162. K.C. Chou, Y.D. Cai, Predicting subcellular localization of proteins by hybridizing functional domain composition and pseudo amino acid composition, J. Cell. Biochem., 91 (2004) 1197-1203.

163. Y. Gao, S.H. Shao, X. Xiao, Y.S. Ding, Y.S. Huang, Z.D. Huang, K.C. Chou, Using pseudo amino acid composition to predict protein subcellular location: approached with Lyapunov index, Bessel function, and Chebyshev filter, Amino Acids, 28 (2005) 373-376. 
164. X. Xiao, S. Shao, Y. Ding, Z. Huang, Y. Huang, K.C. Chou, Using complexity measure factor to predict protein subcellular location, Amino Acids, 28 (2005) 57-61.

165. K.C. Chou, H.B. Shen, Predicting protein subcellular location by fusing multiple classifiers, J. Cell. Biochem., 99 (2006) 517-527.

166. K.C. Chou, H.B. Shen, Hum-PLoc: A novel ensemble classifier for predicting human protein subcellular localization, Biochem. Biophys. Res. Commun. (BBRC), 347 (2006) 150-157.

167. K.C. Chou, H.B. Shen, Predicting eukaryotic protein subcellular location by fusing optimized evidence-theoretic K-nearest neighbor classifiers, Journal of Proteome Research, 5 (2006) 1888-1897.

168. K.C. Chou, H.B. Shen, Addendum to "Hum-PLoc: A novel ensemble classifier for predicting human protein subcellular localization”, Biochem. Biophys. Res. Commun. (BBRC), 348 (2006) 1479.

169. X. Xiao, S.H. Shao, Y.S. Ding, Z.D. Huang, K.C. Chou, Using cellular automata images and pseudo amino acid composition to predict protein subcellular location, Amino Acids, 30 (2006) 49-54.

170. K.C. Chou, H.B. Shen, Euk-mPLoc: a fusion classifier for large-scale eukaryotic protein subcellular location prediction by incorporating multiple sites, Journal of Proteome Research, 6 (2007) 1728-1734.

171. K.C. Chou, H.B. Shen, Recent progresses in protein subcellular location prediction, Anal. Biochem., 370 (2007) $1-16$.

172. H.B. Shen, K.C. Chou, Gpos-PLoc: an ensemble classifier for predicting subcellular localization of Gram-positive bacterial proteins, Protein Engineering, Design, and Selection, 20 (2007) 39-46.

173. H.B. Shen, J. Yang, K.C. Chou, Review: Methodology development for predicting subcellular localization and other attributes of proteins, Expert Review of Proteomics, 4 (2007) 453-463.

174. K.C. Chou, H.B. Shen, Cell-PLoc: A package of Web servers for predicting subcellular localization of proteins in various organisms, Nature Protocols, 3 (2008) 153-162.

175. H.B. Shen, K.C. Chou, A top-down approach to enhance the power of predicting human protein subcellular localization: Hum-mPLoc 2.0, Anal. Biochem., 394 (2009) 269-274.

176. H.B. Shen, K.C. Chou, Gpos-mPLoc: A top-down approach to improve the quality of predicting subcellular localization of Gram-positive bacterial proteins, Protein \& Peptide Letters, 16 (2009) 1478-1484.

177. K.C. Chou, H.B. Shen, Cell-PLoc 2.0: An improved package of web-servers for predicting subcellular localization of proteins in various organisms, Natural Science, 2 (2010) 1090-1103.

178. H.B. Shen, K.C. Chou, Gneg-mPLoc: A top-down strategy to enhance the quality of predicting subcellular localization of Gram-negative bacterial proteins, Journal of Theoretical Biology, 264 (2010) 326-333.

179. S.B. Wan, L.L. Hu, S. Niu, K. Wang, Y.D. Cai, K.C. Chou, Identification of multiple subcellular locations for proteins in budding yeast, Current Bioinformatics, 6 (2011) 71-80.

180. K.C. Chou, Z.C. Wu, X. Xiao, iLoc-Hum: Using accumulation-label scale to predict subcellular locations of human proteins with both single and multiple sites, Molecular Biosystems, 8 (2012) 629-641.

181. W.Z. Lin, J.A. Fang, X. Xiao, K.C. Chou, iLoc-Animal: A multi-label learning classifier for predicting subcellular localization of animal proteins Molecular BioSystems, 9 (2013) 634-644.

182. X. Cheng, X. Xiao, K.C. Chou, pLoc-mPlant: predict subcellular localization of multi-location plant proteins via incorporating the optimal GO information into general PseAAC, Molecular BioSystems, 13 (2017) 1722-1727.

183. X. Cheng, X. Xiao, K.C. Chou, pLoc-mVirus: predict subcellular localization of multi-location virus proteins via incorporating the optimal GO information into general PseAAC, Gene (Erratum: ibid., 2018, Vol.644, 156-156), 628 (2017) 315-321.

184. X. Cheng, S.G. Zhao, W.Z. Lin, X. Xiao, K.C. Chou, pLoc-mAnimal: predict subcellular localization of animal 
proteins with both single and multiple sites, Bioinformatics, 33 (2017) 3524-3531.

185. X. Xiao, X. Cheng, S. Su, Q. Nao, K.C. Chou, pLoc-mGpos: Incorporate key gene ontology information into general PseAAC for predicting subcellular localization of Gram-positive bacterial proteins, Natural Science, 9 (2017) 330-349.

186. X. Cheng, X. Xiao, K.C. Chou, pLoc-mEuk: Predict subcellular localization of multi-label eukaryotic proteins by extracting the key GO information into general PseAAC, Genomics, 110 (2018) 50-58.

187. X. Cheng, X. Xiao, K.C. Chou, pLoc-mGneg: Predict subcellular localization of Gram-negative bacterial proteins by deep gene ontology learning via general PseAAC, Genomics, 110 (2018) 231-239.

188. X. Cheng, X. Xiao, K.C. Chou, pLoc-mHum: predict subcellular localization of multi-location human proteins via general PseAAC to winnow out the crucial GO information, Bioinformatics, 34 (2018) 1448-1456.

189. X. Cheng, X. Xiao, K.C. Chou, pLoc_bal-mGneg: predict subcellular localization of Gram-negative bacterial proteins by quasi-balancing training dataset and general PseAAC, Journal of Theoretical Biology, 458 (2018) 92-102.

190. X. Cheng, X. Xiao, K.C. Chou, pLoc_bal-mPlant: predict subcellular localization of plant proteins by general PseAAC and balancing training dataset Curr Pharm Des, 24 (2018) 4013-4022.

191. Z.D. Su, Y. Huang, Z.Y. Zhang, Y.W. Zhao, D. Wang, W. Chen, K.C. Chou, H. Lin, iLoc-lncRNA: predict the subcellular location of lncRNAs by incorporating octamer composition into general PseKNC, Bioinformatics, 34 (2018) 4196-4204.

192. X. Cheng, W.Z. Lin, X. Xiao, K.C. Chou, pLoc_bal-mAnimal: predict subcellular localization of animal proteins by balancing training dataset and PseAAC, Bioinformatics, 35 (2019) 398-406.

193. K.C. Chou, Advance in predicting subcellular localization of multi-label proteins and its implication for developing multi-target drugs, Current Medicinal Chemistry 26 (2019) 4918-4943.

194. K.C. Chou, Recent progresses in predicting protein subcellular localization with artificial intelligence tools developed via the 5-steps rule, Medicinal Chemistry, Submitted (2019).

195. K.C. Chou, An insightful recollection for predicting protein subcellular locations in multi-label systems, Natural Science, (2019).

196. K.C. Chou, Recent Progresses in Predicting Protein Subcellular Localization with Artificial Intelligence (AI) Tools Developed Via the 5-Steps Rule, Japanese Journal of Gastroenterology and Hepatology https://www.jjgastrohepto.org/v2issue4.php 2(2019) 1-4.

197. K.C. Chou, The pLoc_bal-mPlant is a Powerful Artificial Intelligence Tool for Predicting the Subcellular Localization of Plant Proteins Purely based on their Sequence Information, Int J Nutr Sci., 4 (2019) 1-4.

198. K.C. Chou, The pLoc_bal-mPlant is a powerful artificial intelligence tool for predicting the subcellular localization of plant proteins purely based on their sequence information, J Stem Cell Res Med, 4 (2019) 1-4.

199. K.C. Chou, The pLoc_bal-mAnimal is a powerful artificial intelligence tool for predicting the subcellular localization of animal proteins based on their sequence information alone, Scientific Journal of Biometrics \& Biostatistics, 2 (2019) 1-13.

200. K.C. Chou, X. Cheng, X. Xiao, pLoc_bal-mHum: predict subcellular localization of human proteins by PseAAC and quasi-balancing training dataset Genomics, 111 (2019) 1274-1282.

201. K.C. Chou, X. Cheng, X. Xiao, pLoc_bal-mEuk: predict subcellular localization of eukaryotic proteins by general PseAAC and quasi-balancing training dataset, Med Chem, 15 (2019) 472-485.

202. X. Xiao, X. Cheng, G. Chen, Q. Mao, K.C. Chou, pLoc_bal-mGpos: predict subcellular localization of Gram-positive bacterial proteins by quasi-balancing training dataset and PseAAC, Genomics, 111 (2019) 
886-892.

203. K.C. Chou, The pLoc_bal-mGneg Predictor is a Powerful Web-Server for Identifying the Subcellular Localization of Gram-Negative Bacterial Proteins based on their Sequences Information Alone, ijSci, 9 (2020) 27-34.

204. K.C. Chou, The pLoc_bal-mVirus is a powerful artificial intelligence tool for predicting the subcellular localization of virus proteins according to their sequence information alone, J Gent \& Genome, 4 (2020).

205. K.C. Chou, The pLoc_bal-mHum is a Powerful Web-Serve for Predicting the Subcellular Localization of Human Proteins Purely Based on Their Sequence Information, Adv Bioeng Biomed Sci Res, 3 (2020) 1-5.

206. K.C. Chou, The pLoc_bal-mGpos is a powerful artificial intelligence tool for predicting the subcellular localization of Gram-positive bacterial proteins according to their sequence information alone, Glo J of Com Sci and Infor Tec, 2 (2020) 01-13.

207. X.X. Liu, K.C. Chou, pLoc_Deep-mGneg: predict subcellular localization of Gram negative bacterial proteins by deep learning Advances in Bioscience and Biotechnology (ABB) 11 (2020) 141-152.

208. Y.H. Shao, K.C. Chou, pLoc_Deep-mVirus: A CNN Model for Predicting Subcellular Localization of Virus Proteins by Deep Learning, Natural Science, 12 (2020) 1-12.

209. Y.T. Shao, K.C. Chou, pLoc_Deep-mEuk: predict subcellular localization of eukaryotic proteins by deep learning Natural Science, 12 (2020) 1-29.

210. Y.T. Shao, K.C. Chou, pLoc_Deep-mAnimal: A Novel Deep CNN-BLSTM Network to Predict Subcellular Localization of Animal Proteins Natural Science, 12 (2020) 281-291.

211. Y.T. Shao, X.X. Liu, Z. Lu, K.C. Chou, pLoc_Deep-mHum: predict subcellular localization of human proteins by deep learning Natural Science, 12 (2020) 526-547.

212. Y.T. Shao, X.X. Liu, Z. Lu, K.C. Chou, pLoc_Deep-mPlant: predict subcellular localization of plant proteins by deep learning Natural Science 12 (2020) 237-247.

213. K.C. Chou, S. Forsen, Graphical rules for enzyme-catalyzed rate laws, Biochem. J., 187 (1980) $829-835$.

214. K.C. Chou, R.E. Carter, S. Forsen, A new graphical method for deriving rate equations for complicated mechanisms, Chemica Scripta, 18 (1981) 82-86.

215. K.C. Chou, S. Forsen, Graphical rules of steady-state reaction systems, Can. J. Chem., 59 (1981) 737-755.

216. C.T. Zhang, K.C. Chou, Graphic analysis of codon usage strategy in 1490 human proteins, J. Protein Chem., 12 (1993) 329-335.

217. K.C. Chou, Graphic rule for drug metabolism systems, Current Drug Metabolism, 11 (2010) 369-378.

218. Z.C. Wu, X. Xiao, K.C. Chou, 2D-MH: A web-server for generating graphic representation of protein sequences based on the physicochemical properties of their constituent amino acids, J. Theor. Biol., 267 (2010) 29-34.

219. T. Huang, L. Chen, Y.D. Cai, K.C. Chou, Classification and analysis of regulatory pathways using graph property, biochemical and physicochemical property, and functional property, PLoS ONE, 6 (2011) e25297.

220. K.C. Chou, S. Forsen, Diffusion-controlled effects in reversible enzymatic fast reaction system: Critical spherical shell and proximity rate constants, Biophysical Chemistry, 12 (1980) 255-263.

221. K.C. Chou, S. Forsen, G.Q. Zhou, Three schematic rules for deriving apparent rate constants, Chemica Scripta, 16 (1980) 109-113.

222. K.C. Chou, T.T. Li, S. Forsen, The critical spherical shell in enzymatic fast reaction systems, Biophysical Chemistry, 12 (1980) 265-269.

223. K.C. Chou, N.Y. Chen, S. Forsen, The biological functions of low-frequency phonons: 2. Cooperative effects, Chemica Scripta, 18 (1981) 126-132. 
224. K.C. Chou, N.Y. Chen, The biological functions of low-frequency phonons, Scientia Sinica, 20 (1977) 447-457.

225. K.C. Chou, Low-frequency vibrations of helical structures in protein molecules, Biochem. J., 209 (1983) 573-580.

226. K.C. Chou, Identification of low-frequency modes in protein molecules, Biochem. J., 215 (1983) 465-469.

227. G.P. Zhou, M.H. Deng, An extension of Chou's graphic rules for deriving enzyme kinetic equations to systems involving parallel reaction pathways, Biochem. J., 222 (1984) 169-176.

228. K.C. Chou, Biological functions of low-frequency vibrations ( phonons). 3. Helical structures and microenvironment, Biophys. J., 45 (1984) 881-889.

229. K.C. Chou, The biological functions of low-frequency phonons. 4. Resonance effects and allosteric transition, Biophysical Chemistry, 20 (1984) 61-71.

230. K.C. Chou, Low-frequency vibrations of DNA molecules, Biochem. J., 221 (1984) 27-31.

231. K.C. Chou, Low-frequency motions in protein molecules: beta-sheet and beta-barrel, Biophys. J., 48 (1985) 289-297.

232. K.C. Chou, Prediction of a low-frequency mode in bovine pancreatic trypsin inhibitor molecule, International Journal of Biological Macromolecules, 7 (1985) 77-80.

233. K.C. Chou, Y.S. Kiang, The biological functions of low-frequency phonons: 5. A phenomenological theory, Biophysical Chemistry, 22 (1985) 219-235.

234. K.C. Chou, Origin of low-frequency motion in biological macromolecules: A view of recent progress of quasi-continuity model, Biophysical Chemistry, 25 (1986) 105-116.

235. K.C. Chou, The biological functions of low-frequency phonons: 6. A possible dynamic mechanism of allosteric transition in antibody molecules, Biopolymers, 26 (1987) 285-295.

236. K.C. Chou, Review: Low-frequency collective motion in biomacromolecules and its biological functions, Biophysical Chemistry, 30 (1988) 3-48.

237. K.C. Chou, G.M. Maggiora, The biological functions of low-frequency phonons: 7. The impetus for DNA to accommodate intercalators, British Polymer Journal, 20 (1988) 143-148.

238. K.C. Chou, Low-frequency resonance and cooperativity of hemoglobin, Trends Biochem. Sci., 14 (1989) 212-213.

239. K.C. Chou, G.M. Maggiora, B. Mao, Quasi-continuum models of twist-like and accordion-like low-frequency motions in DNA, Biophys. J., 56 (1989) 295-305.

240. I.W. Althaus, J.J. Chou, A.J. Gonzales, M.R. Diebel, K.C. Chou, F.J. Kezdy, D.L. Romero, R.C. Thomas, P.A. Aristoff, W.G. Tarpley, F. Reusser, Kinetic studies with the non-nucleoside human immunodeficiency virus type-1 reverse transcriptase inhibitor U-90152e, Biochem. Pharmacol., 47 (1994) 2017-2028.

241. K.C. Chou, F.J. Kezdy, F. Reusser, Review: Kinetics of processive nucleic acid polymerases and nucleases, Anal. Biochem., 221 (1994) 217-230.

242. K.C. Chou, C.T. Zhang, G.M. Maggiora, Solitary wave dynamics as a mechanism for explaining the internal motion during microtubule growth, Biopolymers, 34 (1994) 143-153.

243. H. Liu, M. Wang, K.C. Chou, Low-frequency Fourier spectrum for predicting membrane protein types, Biochem Biophys Res Commun (BBRC), 336 (2005) 737-739.

244. G. Gordon, Designed Electromagnetic Pulsed Therapy: Clinical Applications, J. Cell. Physiol., 212 (2007) 579-582.

245. J. Andraos, Kinetic plasticity and the determination of product ratios for kinetic schemes leading to multiple 
products without rate laws: new methods based on directed graphs, Can. J. Chem., 86 (2008) 342-357.

246. K.C. Chou, H.B. Shen, FoldRate: A web-server for predicting protein folding rates from primary sequence, The Open Bioinformatics Journal, 3 (2009) 31-50

247. H.B. Shen, J.N. Song, K.C. Chou, Prediction of protein folding rates from primary sequence by fusing multiple sequential features Journal of Biomedical Science and Engineering (JBiSE), 2 (2009) 136-143.

248. J.F. Wang, K.C. Chou, Insight into the molecular switch mechanism of human Rab5a from molecular dynamics simulations, Biochem Biophys Res Commun (BBRC), 390 (2009) 608-612.

249. G. Gordon, Extrinsic electromagnetic fields, low frequency (phonon) vibrations, and control of cell function: a non-linear resonance system, Journal of Biomedical Science and Engineering (JBiSE), 1 (2008) 152-156

250. A. Madkan, M. Blank, E. Elson, K.C. Chou, M.S. Geddis, R. Goodman, Steps to the clinic with ELF EMF Natural Science 1(2009) 157-165.

251. P. Lian, D.Q. Wei, J.F. Wang, K.C. Chou, An allosteric mechanism inferred from molecular dynamics simulations on phospholamban pentamer in lipid membranes, PLoS ONE, 6 (2011) e18587.

252. Q.H. Liao, Q.Z. Gao, J. Wei, K.C. Chou, Docking and Molecular Dynamics Study on the Inhibitory Activity of Novel Inhibitors on Epidermal Growth Factor Receptor (EGFR), Medicinal Chemistry, 7 (2011) 24-31.

253. J. Li, D.Q. Wei, J.F. Wang, Z.T. Yu, K.C. Chou, Molecular Dynamics Simulations of CYP2E1, Medicinal Chemistry, 8 (2012) 208-221.

254. J.F. Wang, K.C. Chou, Recent advances in computational studies on influenza a virus $\mathrm{m} 2$ proton channel, Mini Reviews in Medicinal Chemistry, 12 (2012) 971-978.

255. T. Zhang, D.Q. Wei, K.C. Chou, A Pharmacophore Model Specific to Active Site of CYP1A2 with a Novel Molecular Modeling Explorer and CoMFA, Medicinal Chemistry, 8 (2012) 198-207.

256. J. Jia, Z. Liu, X. Xiao, K.C. Chou, iPPI-Esml: an ensemble classifier for identifying the interactions of proteins by incorporating their physicochemical properties and wavelet transforms into PseAAC, J. Theor. Biol., 377 (2015) 47-56.

257. J. Jia, Z. Liu, X. Xiao, B. Liu, K.C. Chou, Identification of protein-protein binding sites by incorporating the physicochemical properties and stationary wavelet transforms into pseudo amino acid composition (iPPBS-PseAAC), J Biomol Struct Dyn (JBSD) 34 (2016) 1946-1961.

258. K.C. Chou, Proposing pseudo amino acid components is an important milestone for proteome and genome analyses (2019), International Journal for Peptide Research and Therapeutics (IJPRT) 26 (2019) 1085-1098.

259. K.C. Chou, Impacts of pseudo amino acid components and 5-steps rule to proteomics and proteome analysis, Current Topics in Medicinak Chemistry (CTMC) (Special Issue ed. G.P Zhou), 19 (2019) 2283-2300.

260. K.C. Chou, Coronavirus and Gordon Life Science Institute, Natural Science, 12 (2020) 429-440.

261. K.C. Chou, The Implication of "I Am the Alpha and the Omega" to Internet Institutes, Natural Science, 12 (2020) 482-494.

262. K.C. Chou, Noah's Ark and Internet Institutes: When and Why?, Natural Science, 12 (2020) 470-481.

263. K.C. Chou, The Pandemic Pestilences and Internet Institutes, Natural Science, 12 (2020) 495-515. 